\title{
Multi-objective optimal layout of distributed storm-water detention
}

\author{
T. Tao $\cdot$ J. Wang $\cdot$ K. Xin $\cdot$ S. Li
}

Received: 26 July 2012/Revised: 22 February 2013/Accepted: 6 May 2013/Published online: 5 June 2013

(C) Islamic Azad University (IAU) 2013

\begin{abstract}
The determination of locations and sizes for such a system is important in a drainage master plan or a storm-water management system. However, the distribution of detentions in the upstream and midstream is often more dispersed using many combinations of volume scales. This paper uses the non-dominated sorting genetic algorithm combined with the Storm Water Management Model to explore and calculate the optimal layout scheme for decentralized rainwater detention. The purpose is to find a design and planning method that can achieve the optimal balance of decentralized detention considering the aspects of flood disaster control, peak flow reduction, and investment cost. The optimal results of Pareto in applied case show that among the five most unfavourable nodes, the detentions with different layout volumes and relatively smaller size can control water logging from rainstorm. The project cost is effectively reduced and the standard of the return period of the regional rainwater system is enhanced from 2 to 20 years.
\end{abstract}

Keywords Design - Detention - Optimization ·

Storm-water

\section{Introduction}

With the rapid process of urbanization and climate change, extreme weather and heavy rains occur more frequently (Sim and Balamurugan 1991; Kibler et al. 2007; Nirupama and Simonovic 2007). Consequently, many cities in China

T. Tao $\cdot$ J. Wang $\cdot$ K. Xin $(\bowtie) \cdot S$. Li

College of Environmental Science and Engineering,

Tongji University, Shanghai 200092, China

e-mail: xkl@tongji.edu.cn experience more serious waterlogging for the past several years (Xiang and Griffiths 1988; Yuan et al. 2011). The negative impacts of urbanization are increased peak flow rates, loss of natural depression storage, reduction in infiltration capacity in a drainage basin, reduction in natural vegetation, and decreased storm-water runoff (Gottschalk and Weingartner 1998; Gumbo et al. 2002; Guillemette et al. 2005; Nadarajah and Kotz 2007). In the face of intensified disasters of rainstorm, flood, and waterlogging, the relatively backward drainage system can no longer meet the demands of flood control and disaster alleviation. In the engineering and reconstruction of the rainwater drainage system, traditional methods focus on the expansion of drainage network facilities, that is, increasing the pipe diameter or diverting the reconstruction of rain and sewage systems. However, due to the complexity of urban underground pipelines, constructions along the road are not only difficult but also easily cause very costly damages to other facilities and traffic congestion. By contrast, transforming the system via rainwater detention is less complex in terms of construction (Cembrano et al. 2004; Scholz 2004; Lee and Li 2009). It can also be environmentally protective by controlling nonpoint source pollution and promoting the use of rainwater resources in addition to flood control (Kowalski et al. 1999; Persson et al. 1999). It is in line with the concept of low impact development of source reduction as well as process control and is thus receiving increasing attention.

Detention basins are man-made storage structures intended to mitigate the negative impacts of urbanization on storm drainage. The determination of locations and sizes for such a system is important in a drainage master plan or a storm-water management system (Lessard and Beck 1991; Segarra 1995; Persson 2000). Different positions of storage facilities often have different functions. A detention 
is set in the discharge outlet of a rainwater system and is often installed together with a rainwater pumping station. This setup reduces not only the peak flow at the discharge outlet, but also the capacity of the rainwater pumping station. Although its control effect of nonpoint source pollution is significant, it is limited to the abatement of the upstream peak flow. The settings of storage facilities in the upstream and midstream mainly function in flow regulation by reducing the peak flow and are able to withstand water logging disasters in areas covered by the rainwater system. However, the distribution of detentions in the upstream and midstream is often more dispersed using many combinations of volume scales. Systematic research with integration and multi-objection (Engeland et al. 2006; Rié Komuro et al. 2006; Fu et al. 2008) must be carried out to determine the layout scheme of the detention. The decentralized detention should maximize the benefits by considering not only the rainstorm and flood control effects on the upstream region, but also the drainage load in the downstream region to pursue the economic efficiency of the project. Thus, considering detention basins as a network, rather than individually, are critical to successful flood reduction (Travis and Mays 2008).

There are several studies which consider the optimality in detention basin networks and utilized the programming method (Mays and Bedient 1982; Brummer 1995; Papa and Adams 1997; Behera et al. 1999; Rathnam et al. 2002; Kaini et al. 2007). In recent years, the development of modern meta-heuristic search techniques, such as genetic algorithms and scatter search, has attracted much attention from researchers wanting to address the real-world planning/design issues. Yeh and Labadie (1997) utilized successive reaching dynamic programming and a multiobjective genetic algorithm to optimize multi-purpose detention systems. Zhen et al. (2004) considered the problem using multiple simulation models linked by heuristic optimization techniques and a scatter search algorithm. Overall, most of these studies attempt to locate the detention in a cost objective and need a computationally expensive evaluator of optimization problems. Because of non-dominated sorting genetic algorithm method is expected to find the near optimal solution in a more efficient way and therefore serves as a better optimization engine. It has been applied to optimization problems of complex systems. Therefore, this research combines multiobjective optimization methods with the Storm Water Management Model (SWMM) (Rossman 2004; Suhyung and Minock 2007) of the United States Environmental Protection Agency (USEPA) for the layout study of decentralized detention, which allows the selection of the optimal solution based on different conditions. Another purpose is to determine the best relationships among multiple objectives as well as provide a scientific basis for project assessment and planning. The methodology is presented in the next section, followed by the applications to the case study. This case study is the subsystem of rainwater on JF road for one of the separate rainwater systems of the drainage network system of ZJ city, China. The subsystem models of rainwater on JF road include 74 subcatchments, 79 pipes, 79 nodes, and one drainage outlet.

\section{Materials and methods}

Multi-objective model

A comprehensive consideration of the location and size of decentralized detention is required to improve the rainwater system. Generally, a higher number of detentions result in a higher total volume. A greater area of rainstorm and flood control also corresponds to a stronger function for the reduction in downstream peak flow and, thus, higher costs. The cost and ability of rainstorm and flood control are two indicators of increase and decrease. All aspects must be examined to set the layout scheme so that the two indicators can be as optimal as possible and obtain the best balance and optimal combination of the collection.

Accordingly, the multi-objective optimization objective function, constraints, and variables established in this study are as follows:

Objective function:

min Cost

$\min$ Peakflow $=f_{1}\left(S_{1}, S_{2}, \ldots S_{n}\right)$,

Subject to:

$0 \leq S_{i} \leq 800$

$f_{2}\left(S_{1}, S_{2}, \ldots S_{n}\right)=0$, variables : $S_{i}(i=1,2,3, \ldots n)$

\section{SWMM model}

where $S_{i}$ is the detention size $\left(\mathrm{m}^{2}\right)$ of ${ }_{i}\left(S_{i}=0\right.$ means no detention layout), $n$ is the detention number, $f_{1}()$ is the peak flow function of the downstream specific location during SWMM calculations, $f_{2}()$ is the number function of the waterlog node during SWMM calculations. The SWMM model shows that the internal bottom elevation and connection are constrained by a variety of conditions.

Non-dominated sorting genetic algorithm (NSGA-II)

A controlled elitist non-dominated sorting genetic algorithm controlled elitist NSGA is used in this study for the multi-objective optimization problem. Non-dominated sorting genetic algorithm method (NSGAII) (Deb et al. 2002; Iqbal and Guria 2009; Hong 2010) outperformed 
other techniques in satisfying both goals of Pareto multiobjective optimization (closeness to Pareto front and diversity among solutions in each front). NSGA-II adopts the parent-and-offspring combination to retain the optimal individuals, proposes a new sorting order of fast nondominated algorithm based on classification, and reduces the computational complexity of $O\left(m N^{3}\right)-O\left(m N^{2}\right)$. It introduces the concept of crowded distance to place the shared parameters. On the one hand, it avoids the complex work of confirmed shared parameters. On the other hand, it increases the diversity of the evolved populations. Nondominated sorting strategy in NSGA-II is shown in Fig. 1. In this paper, the Qt Creator is selected as the integrated development environment, and the calling module of the SWMM model is embedded in the NSGA-II algorithm to construct the $\mathrm{C}++$ language program for the layout model of detention optimization. The calculation of this model is shown in Fig. 2.

\section{Results and discussion}

An actual example of the project is the subsystem of rainwater on JF road for one of the separate rainwater systems of the drainage network system of ZJ city, China. The subsystem models of rainwater on JF road include 74 subcatchments, 79 pipes, 79 nodes, and one drainage outlet, and the parameters in SWMM model is shown in

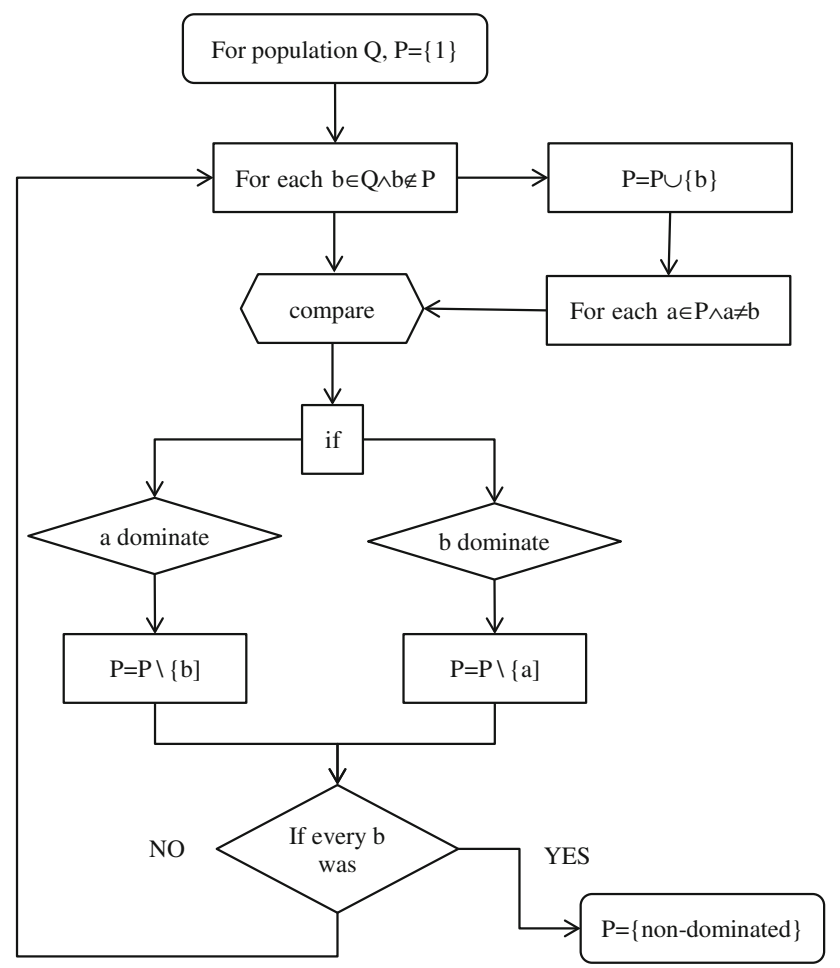

Fig. 1 Non-dominated sorting strategy in NSGA-II

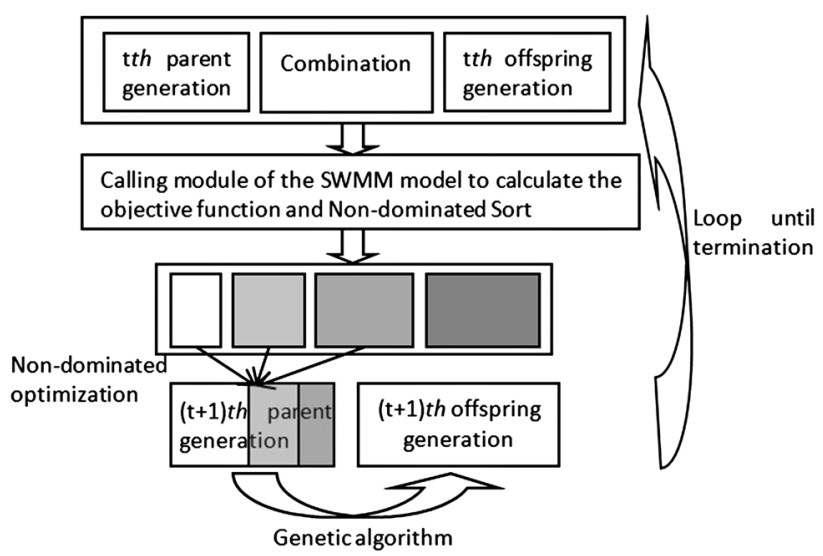

Fig. 2 The calculation flow chart

Table 1. All pipes are composed of separate storm sewer systems.

In this case study, it consults the Costs equation [Eq.(1)] of Young (1997) and combined with the dug and preparation costs in $\ll Z J$ Municipal Engineering Estimate Indicators $\gg$, the cost of single detention is determined as one of the objective function, shown as Eq.(2)

Cost $=2.195 \times 10^{4}$ Volume $^{0.69}$

Cost $=\sum_{i=1}^{n}\left(2000\right.$ Volume $\left._{i}\left(S_{i}\right)^{0.69}+500 S_{i}+g\left(S_{i}\right)\right)$

where $S_{i}$ is the detention size $\left(\mathrm{m}^{2}\right)$ of ${ }_{i}\left(S_{i}=0\right.$ means no detention layout), $n$ is the detention number, Volume $_{i}$ is the volume $\left(\mathrm{m}^{3}\right)$ of the $i$ detention, and the internal bottom elevation is set to be the same as that of the node in the model of detention. Thus, Volume $i$ is the product of the $S_{i}$ and $H_{i}$ of the depth of the original inspection well, where $H_{i}$ is a constant.

The Chicago approach is used to design a synthetic hyetograph based on the parameters of the storm intensity

Table 1 The parameters in SWMM model

\begin{tabular}{ll}
\hline Parameters & Value \\
\hline Area of subcatchment & $\ngtr 2$ ha \\
Per cent of Impervious area & $70-90 \%$ \\
Mannings N for Impervious area & 0.030 \\
Mannings N for pervious area & 0.015 \\
Dstore-Imperv & $2-5 \mathrm{~mm}$ \\
Dstore-perv & $3-10 \mathrm{~mm}$ \\
Horton equation & \\
Max infiltration rate & 76.2 \\
Min infiltration rate & 3.18 \\
Decay coefficient & 0.0006 \\
Zero-Imperv & $5-\%$ \\
Manning's roughness of concrete & $0.013-0.015$ \\
\hline
\end{tabular}




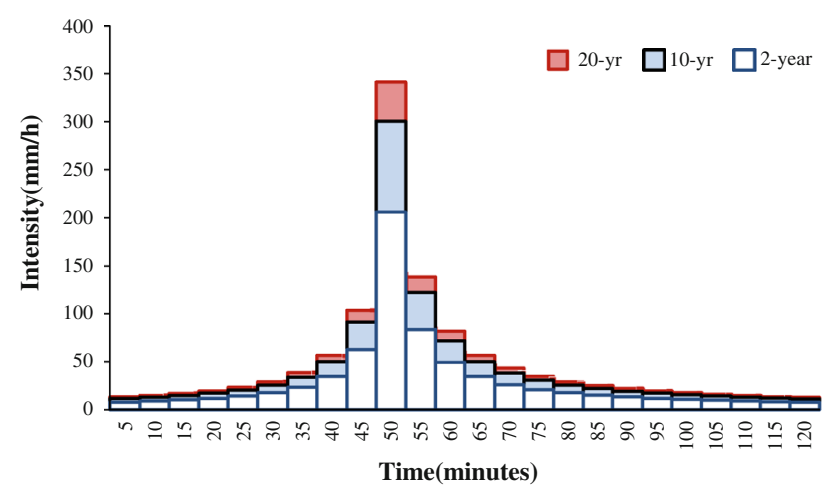

Fig. 3 Design storm hyetographs

formula, shown in Fig. 3. According to $\ll$ Code for design of outdoor wastewater engineering $\gg$ (GB50014-2011) in China, the design standard of water drainage system is from 2-year return period to 20-year period based on the importance of the design areas. The case of rainstorm occurrence with 2- or 20-year return periods is used to design and simulates the drainage simulation of the subsystem separately, and the peak rainfall and average rainfall are shown in Table 2. Under the condition of rainstorm in the 2-year return period, only the node of J123 has a minor flooding situation, and there is no such occurrence for the remaining nodes. In other words, the system can basically withstand the impact of the intensity of a rainstorm with a 2-year return period. In the case of a rainstorm with a 20-year return period, most areas of the upstream of the rainwater system have floods, among which J120, J121, $\mathrm{J} 123, \mathrm{~J} 130, \mathrm{~J} 138$, and $\mathrm{J} 139$ experience the most serious flooding situations. With an average lasting time of more than $20 \mathrm{~min}$, the time for the nodes to begin being flooded is from 5 to $10 \mathrm{~min}$, which is $48 \mathrm{~min}$ after the rainfall peak. The flow peak and pipe load conditions of the nodes at 53 min are shown in Fig. 4.

An analysis of Fig. 4 reveals that the weakest link of the area rainwater system is mainly concentrated in sections A to $\mathrm{C}$ of the upstream, and the culvert drainage capacity of the downstream region is slightly higher, which is still in a good operating condition for a 20 -year return period of rainstorm intensity. Thus, the drainage facilities of sections A to $\mathrm{C}$ need to improve the overall ability of the storm-

Table 2 Rainfall and intensity of design storm

\begin{tabular}{llll}
\hline $\begin{array}{l}\text { Design storm } \\
\text { (years })\end{array}$ & $\begin{array}{l}\text { Total rainfall } \\
(\mathrm{mm})\end{array}$ & $\begin{array}{l}\text { Peak rainfall } \\
(\mathrm{mm} / \mathrm{h})\end{array}$ & $\begin{array}{l}\text { Average rainfall } \\
(\mathrm{mm} / \mathrm{h})\end{array}$ \\
\hline 2 & 59.2 & 205.7 & 29.6 \\
10 & 86.5 & 300.6 & 43.3 \\
20 & 99.3 & 341.4 & 49.2 \\
\hline
\end{tabular}

water resistance of rainwater subsystems on JF road. By setting the detention of the above zones in the area to improve the drainage capacity of the rainwater system, the area has no waterlog under the design of the 20-year return period of rainstorm intensity, and the peak flow at the discharge place of the downstream is decreased to some extent.

In the models, the main reasons for the occurrence of node waterlogging are as follows: (1) the node, especially the connection point of the catchment area, bears a very large amount of the entrance flow of rainwater and (2) the pipe size or slope of the downstream nodes is insufficient and results in limited drainage capacity. Considering that $\mathrm{J} 135, \mathrm{~J} 138, \mathrm{~J} 123$, as well as J119 and J14 are the connection points of the catchment area, and with the occurrence of a larger waterlog, the downstream pipe of the nodes is in high load. The storm-water detention in these nodes can very effectively disperse to collect the overload waterlog. Therefore, the reconstruction programme is positioned at the detention that has been determined for the setting scale of the above five nodes to enhance the ability of the system, as shown in Fig. 5.

The proposed optimization model is used in calculations to save investment costs for the detention, reduces downstream peak flows of the transformation region (considering the peak flow of culvert C137), and meets the optimal balance programme for the three objectives of no waterlogging at the nodes. The peak flow at culvert $\mathrm{C} 137$ is $550.3 \mathrm{~L} / \mathrm{s}$ prior to the layout of the detention.

The first generation is the population randomly generated by the initialization of the computer program, and the distribution relationship of the two objective functions of their individual space is shown in Fig. 6. All individuals in the population do not meet the constraints, and the lowest level of non-domination is 20 . The peak flows range from a minimum of $378 \mathrm{~L} / \mathrm{s}$ to a maximum of $495 \mathrm{~L} / \mathrm{s}$ with a smaller fluctuation range, and the corresponding cost range is from a minimum of 610,000 to a maximum of 2.11 million with a larger fluctuation range. The first-generation population randomly generated is more discrete and disorderly in the space of two objective functions, instead of showing a certain change trend. A kind of cost value corresponds to different peak flows under many circumstances, and all these individuals do not meet the constraints; thus, there are many optimizations and evolution space.

When the population evolves to the 25th generation, the infeasible solutions are completely eliminated and the population that appears are all with feasible solutions, shown as Fig. 7. There are a total of four non-dominated levels for feasible solutions with the distribution in a smaller range. The lowest peak flow is $387 \mathrm{~L} / \mathrm{s}$, and the 


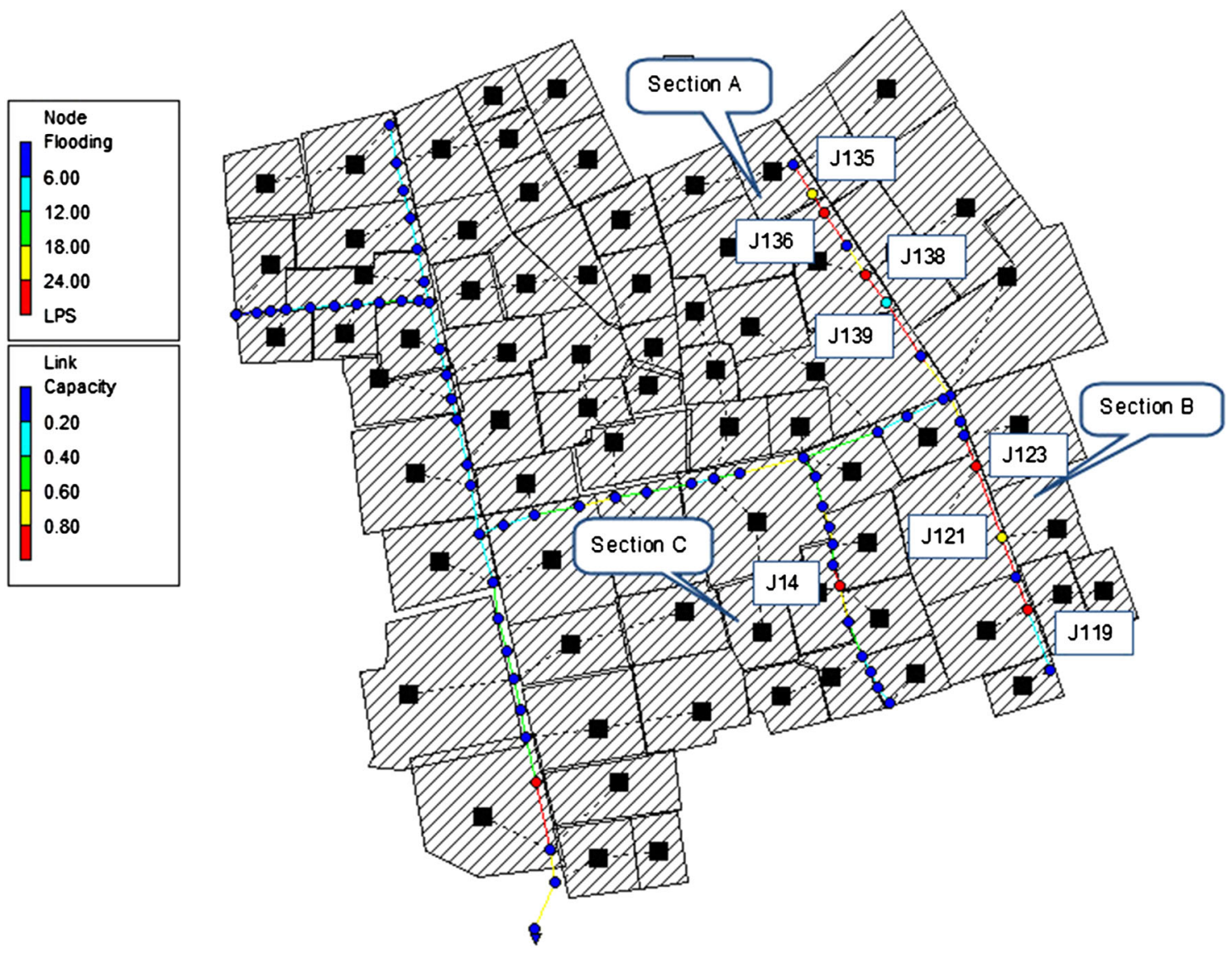

Fig. 4 The peak flow of the nodes

highest peak flow is $464 \mathrm{~L} / \mathrm{s}$; the minimum cost is 1.65 million, and the highest cost is 2.21 million. Different from the non-feasible solution of the first generation randomly generated, the cost of feasible distribution has a significant increasing and decreasing relationship with the peak flow.

The 50th generation of the population shows the optimal front shape of Pareto in the spatial distribution of the objective function, with only one non-dominated level, shown as Fig. 8. The lowest peak flow is $387 \mathrm{~L} / \mathrm{s}$, and the corresponding maximum cost is 2.11 million; the minimum cost is 1.65 million, and the corresponding highest peak flow is $463 \mathrm{~L} / \mathrm{s}$. Compared with the 25 th generation of the population, the 50th generation of the optimal population has performed optimization in two ways. First, a better individual is created. For example, point $C(418,177)$ of the first level in Fig. 8 is better than point A $(430,182)$ of the first level in Fig. 7. Second, some non-dominated solutions are eliminated. Third, a more uniform distribution of the optimal front of Pareto is made. In calculating the termination condition when the population evolved to the 50th generation, Figs. 7 and 8 indicate that in the evolutionary process of the 25th-50th generations, the propulsion of the front line of Pareto is not obvious. The main function of the optimization is to increase the number of individuals at the front line of Pareto, reduces local congestion, and unifies the individual distribution.

Three points B, C, and D in Fig. 8 are selected as the optimal solution, and the representative of the three different intervals is used as the analysis object.

Table 3 implies the following:

1. The arrangements of the three detentions of $\mathrm{B}, \mathrm{C}$, and $\mathrm{D}$ can reduce the peak flow of the regional segment of C137 from $550 \mathrm{~L} / \mathrm{s}$ to below $470 \mathrm{~L} / \mathrm{s}$ in the case of a of heavy rainstorm with a 20 -year return period. Consequently, waterlogging does not occur in the upstream nodes, and the downstream does not experience an overload drainage condition. Hence, standards of the regional rainwater system must be designed to be enhanced from a return period 2-20 years, which can successfully improve the standards for transformation under the condition of no renovation construction of rainwater pipes.

2. The distribution range of the peak flow in the optimal results is relatively narrower with a floating range of $76 \mathrm{~L} / \mathrm{s}$. This finding is due to the initial population 
Fig. 5 Layout of distributed detention

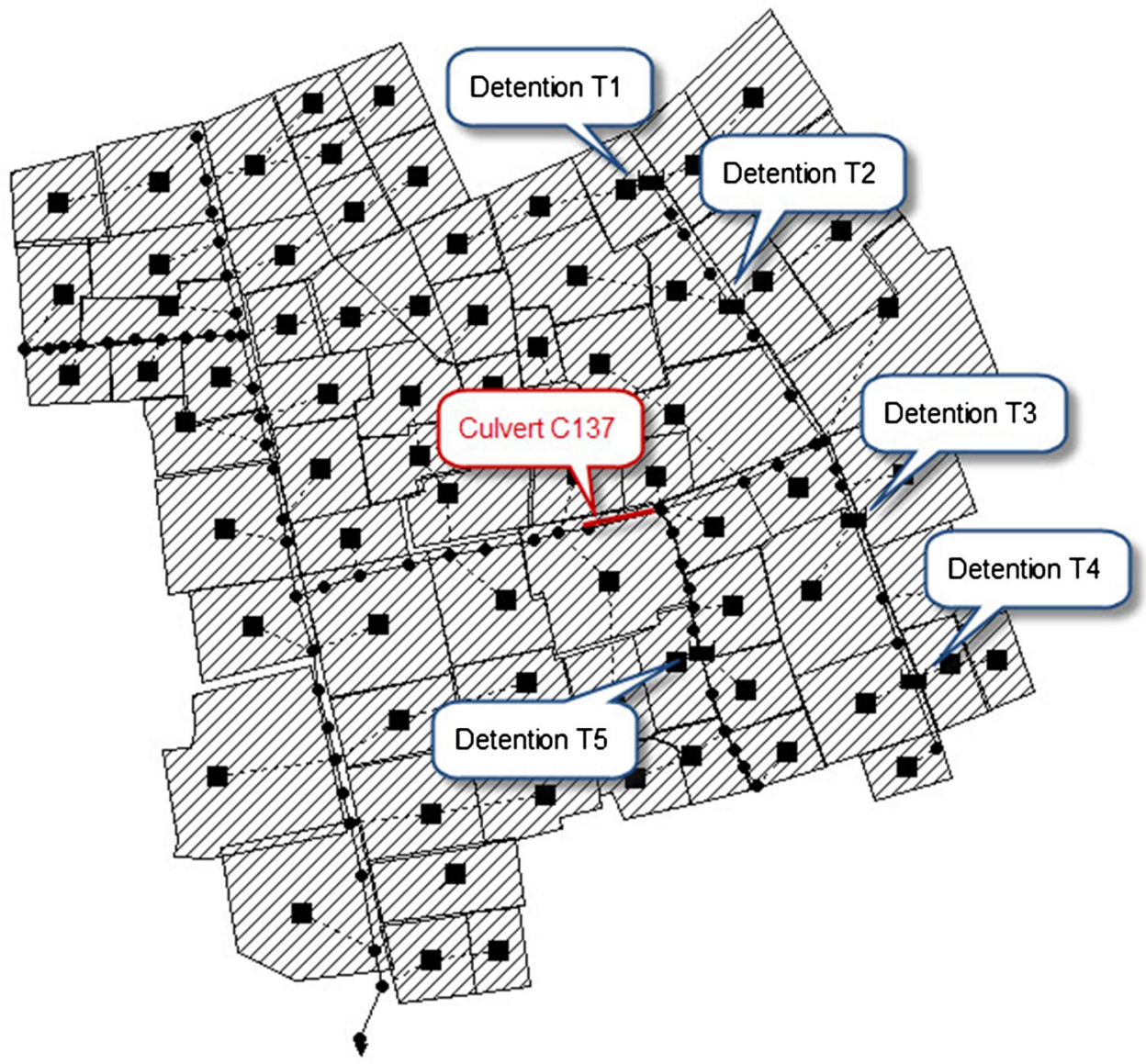

The distribution of 1st generation

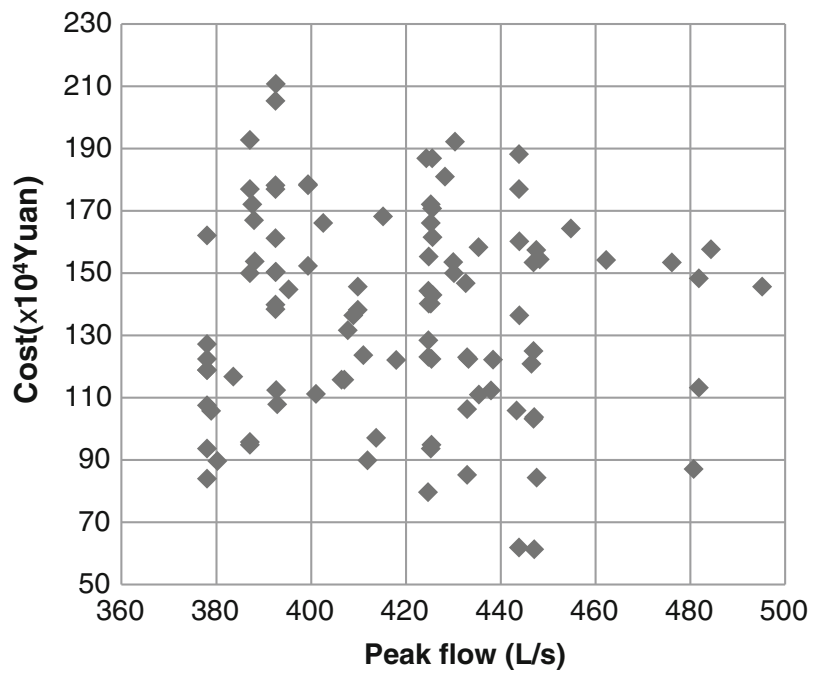

Fig. 6 The distribution of $1^{\text {st }}$ generation in optimal process

that begins to evolve from the infeasible solutions (with constraints towards the scale of the facilities). If the evolved individuals meet the constraints concentrated on the junction of the feasible and infeasible solutions of individuals within a small range, and the
The distribution of 25th generation

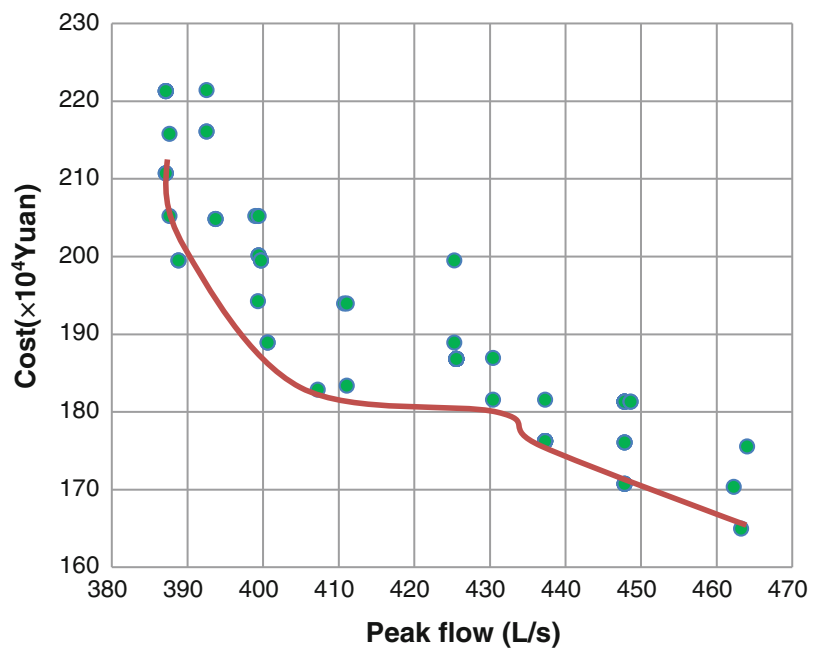

Fig. 7 The distribution of $25^{\text {th }}$ generation in optimal process

facility scale cannot be unlimitedly increased, the peak flow exceeds a certain value. On the other hand, when the upstream nodes have no waterlogging occurrence, the peak flow is also reduced to a certain extent. 


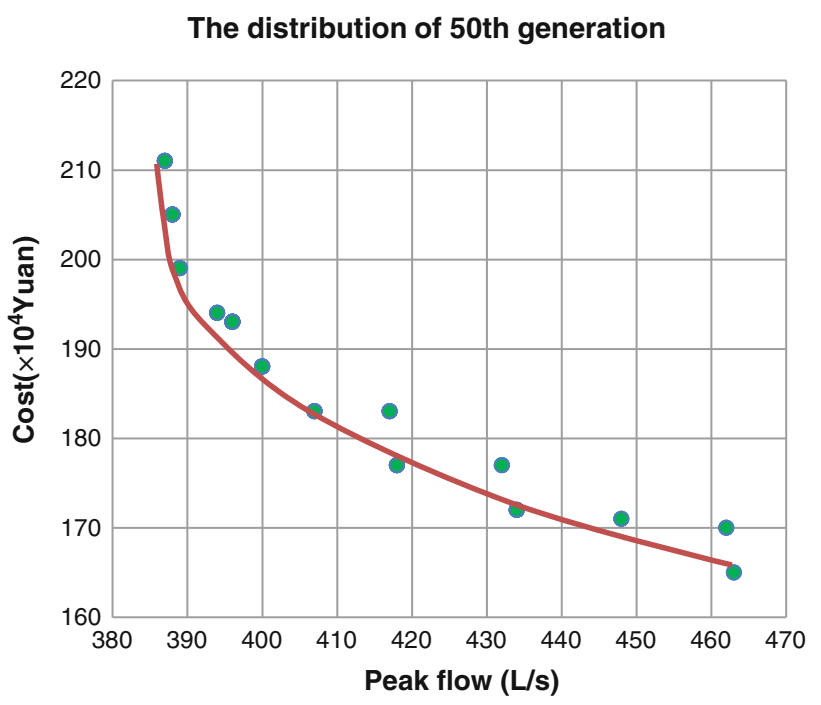

Fig. 8 The distribution of $50^{\text {th }}$ generation in optimal process

Table 3 List of optimal schemes

\begin{tabular}{llllllll}
\hline Scheme no. & $\begin{array}{l}\text { Peak flow } \\
\text { (L/s) }\end{array}$ & $\begin{array}{l}\text { Costs (ten } \\
\text { thousand) }\end{array}$ & \multicolumn{5}{c}{ Area of detention $\left(\mathrm{m}^{2}\right)$} \\
\cline { 5 - 8 } & & & $\mathrm{T} 1$ & $\mathrm{~T} 2$ & $\mathrm{~T} 3$ & $\mathrm{~T} 4$ & $\mathrm{~T} 5$ \\
\hline B & 387 & 211 & 500 & 700 & 500 & 500 & 600 \\
$\mathrm{C}$ & 418 & 177 & 500 & 700 & 200 & 500 & 500 \\
$\mathrm{D}$ & 463 & 165 & 500 & 700 & 100 & 500 & 300 \\
\hline
\end{tabular}

3. Among the three programmes, the detention areas of $\mathrm{T} 1, \mathrm{~T} 2$, and T4 have consistencies of 500, 700, and $500 \mathrm{~m}^{2}$, respectively. This result demonstrates that the detention area sizes of $\mathrm{T} 1, \mathrm{~T} 2$, and $\mathrm{T} 4$ have little impact on the downstream peak flow, and the determination process of its area is the balanced result of the non-flood conditions and lowest cost. The sizes of detention of $\mathrm{T} 3$ and $\mathrm{T} 5$ have more significant impacts on the downstream peak flow, which has a direct relation to its location near the downstream.

4. A comparison of programmes $\mathrm{B}$ and $\mathrm{D}$ reveals that when the cost is increased by $27.8 \%$, the reduction in peak flow is $16.4 \%$. Comparing programmes $\mathrm{C}$ and $\mathrm{D}$ show that when the cost rises by $7.3 \%$, the peak flow reduction is almost $10 \%$. Comparing programmes $\mathrm{B}$ and $\mathrm{C}$ suggests that when the cost is increased by $19.2 \%$, the peak flow reduction is only $8 \%$. Therefore, if the two objectives are weighed from the perspective of investment effectiveness, the $\mathrm{C}$ programme can be considered as the optimal layout of the detention. However, the renovation construction of the detention needs to occupy a vast ground area or underground space, which is bound to affect the comprehensive utilization of land together with the landscape, thereby limiting the layout of the other municipal facilities. The selection and implementation of specific programmes also be combined with specific conditions as well as the policies and regulations of the relevant departments in a locality to carry out comprehensive and integrated planning.

\section{Conclusion}

This paper uses the elite NSGA-II combined with the SWMM model to explore and calculates the optimal layout scheme for decentralized rainwater detention. The purpose is to find a design and planning method that can achieve the optimal balance of decentralized detention considering the aspects of flood disaster control, peak flow reduction, and investment cost.

The methods proposed in this paper were applied in a real project. Five detentions of the model that are most vulnerable to the occurrence of flood, and the settings of the most unfavourable node connected to the catchment area to improve the system are selected. The objective function for the corresponding cost is constructed, and the peak flow function as well as rainstorm and constraints are established to determine the best scale setting scheme. The obtained optimal results of Pareto show that among the five most unfavourable nodes, the detentions with different layout volumes and relatively smaller size can control water logging from rainstorm and flood. The project cost is effectively reduced, and the standard of the return period of the regional rainwater system is enhanced from 2- to 20-year intervals.

This paper has only investigated two optimal objectives of the flood control effect and cost of peak flow detentions. In recent years, many researchers have studied multi-purpose storage tanks focusing on regulating the peak flow of rainstorms, together with the combination of flood and pollution control. The pollution control objective of the storage tank will be taken into account in future research, in accordance with the latest concept of rainstorm and flood management.

Acknowledgments Funding support from The Major Science and Technology Project-Water Pollution Control and Treatment (No. 2009ZX07317-008).

\section{References}

Behera PK, Papa F, Adams BJ (1999) Optimization of regional stormwater management systems. Journal of Water Resource Planning and Management 125(2):107-114

Brummer J (1995) A constructive solution for optimal local control of runoff events. Math Comput Simul 39(1):39-52 
Cembrano G, Quevedo J, Salamero M, Puig V, Figueras J, Martí J (2004) Optimal control of urban drainage systems. A case study. Control Eng Pract 12(1):1-9

Deb K, Pratap A, Agarwal S, Meyarivan T (2002) A fast and elitist multiobjective genetic algorithm: Nsga-Ii. Evolutionary computation. IEEE Trans 6(2):182-197

Engeland Kolbjørn, Braud Isabelle, Gottschalk Lars, Leblois Etienne (2006) Multi-objective regional modelling. J Hydrol 327(3-4): 339-351

Fu Guangtao, Butler David, Khu Soon-Thiam (2008) Multiple objective optimal control of integrated urban wastewater systems. Environ Model Softw 23(2):225-234

Gottschalk Lars, Weingartner Rolf (1998) Distribution of peak flow derived from a distribution of rainfall volume and runoff coefficient, and a unit hydrograph. J Hydrol 208(3-4):148-162

Guillemette François, Plamondon André P, Prévost Marcel, Lévesque Denis (2005) Rainfall generated stormflow response to clearcutting a boreal forest: peak flow comparison with 50 world-wide basin studies. J Hydrol 302(1-4):137-153

Gumbo Bekithemba, Munyamba Nelson, Sithole George, Savenije HHG (2002) Coupling of digital elevation model and rainfallrunoff model in storm drainage network design. Phys Chem Earth, Parts A/B/C 27(11-22):755-764

Hong Yao-Ming (2010) Experimental evaluation of design methods for in-site detention ponds. Int J Sedim Res 25(1):52-63

Iqbal Jawed, Guria Chandan (2009) Optimization of an operating domestic wastewater treatment plant using elitist non-dominated sorting genetic algorithm. Chem Eng Res Des 87(11):1481-1496

Kaini P, Artita K, Nicklow JW (2007) Evaluating optimal detention pond locations at a watershed scale. World environmental and water resources congress 2007: restoring our natural habitat, 2007 ASCE

Kibler DF, Froelich CD, Aron G (2007) Analyzing urbanization impacts on Pennsylvania flood peaks. J Am Water Resour Assoc 17(2):270-274

Kowalski R, Reuber J, Köngeter J (1999) Investigations into and optimisation of the performance of sewage detention tanks during storm rainfall events. Water Sci Technol 39(2):43-52

Lee Jae Su, Li Ming-Han (2009) The impact of detention basin design on residential property value: case studies using gis in the hedonic price modeling. Landsc Urban Plan 89(1-2):7-16

Lessard P, Beck MB (1991) Dynamic simulation of storm tanks. Water Res 25(4):375-391

Mays LW, Bedient PB (1982) Model for optimal size and location of detention. J Water Resour Plann Manage 108(3):270-285
Nadarajah Saralees, Kotz Samuel (2007) Exact distribution of the peak runoff. J Hydrol 338(3-4):325-327

Nirupama N, Simonovic SP (2007) Increase of flood risk due to urbanization: a Canadian example. Nat Hazards 40:25-41

Papa Fabian, Adams Barry J (1997) Application of derived probability and dynamic programming techniques to planning regional stormwater management systems. Water Sci Technol 36(5): $227-234$

Persson J (2000) The hydraulic performance of ponds of various layouts. Urban Water 2(3):243-250

Persson J, Somes NLG, Wong THF (1999) Hydraulics efficiency of constructed wetlands and ponds. Water Sci Technol 40(3): 291-300

Rathnam EV, Mahammad Abdulla S, Jayakumar KV (2002) Urban runoff estimation and optimization of stormwater detention systems-a case study for Hyderabad city. India, Urban Drainage

Rié Komuro E, Ford David, Reynolds Joel H (2006) The use of multicriteria assessment in developing a process model. Ecol Model 197(3-4):320-330

LA Rossman (2004) Storm water management model user's manual (Version 5.0)

Scholz Miklas (2004) Case study: design, operation, maintenance and water quality management of sustainable storm water ponds for roof runoff. Bioresour Technol 95(3):269-279

Segarra Rafael I (1995) Optimal design of runoff storage/release systems. Water Sci Technol 32(1):193-199

Sim Low Kwai, Balamurugan G (1991) Urbanization and urban water problems in southeast Asia a case of unsustainable development. J Environ Manage 32(3):195-209

Suhyung J, Minock C (2007) Using SWMM as a tool for hydrologic impact assessment. Desalination 212:344-356

Travis Quentin B, Mays Larry W (2008) Optimizing retention basin networks. J Water Resour Plann Manage 134(5):432-439

Xiang S, Griffiths John F (1988) A survey of agrometeorological disasters in south China. Agric For Meteorol 43(3-4):261-276

Yeh CH, Labadie JW (1997) Multiobjective watershed-level planning of storm water detention systems. J Water Resour Plann Manage 123(6):336-343

Yuan Lin, Zhang Liquan, Xiao Derong, Huang Huamei (2011) The application of cutting plus waterlogging to control spartina alterniflora On Saltmarshes in the Yangtze estuary, China. Estuar Coast Shelf Sci 92(1):103-110

Zhen X-Y, Yu S-L, Lin J-Y (2004) Optimal location and sizing of stormwater basins at watershed scale. J Water Resour Plann Manage 130(4):339-347 